\title{
Unraveling the Redox Behavior of a CoMoS Hydrodesulfurization Catalyst: A Scanning Transmission X-ray Microscopy Study in the Tender X-ray Range
}

\author{
Mustafa Al Samarai, ${ }^{\dagger}$ Florian Meirer, ${ }^{\dagger}$ Chithra Karunakaran, ${ }^{\ddagger}$ Jian Wang, ${ }^{\ddagger}$ Eelco T. C. Vogt, \\ Henny W. Zandbergen, ${ }^{\S}$ Thomas Weber, ${ }^{\perp}$ Bert M. Weckhuysen, ${ }^{\dagger}$ and Frank M. F. de Groot* ${ }^{*}$ \\ ${ }^{\dagger}$ Inorganic Chemistry \& Catalysis, Debye Institute for Nanomaterials Science, Utrecht University, Universiteitsweg 99,3584 CG \\ Utrecht, Netherlands \\ ${ }^{\ddagger}$ Soft X-ray Spectromicroscopy, Canadian Light Source Inc., University of Saskatchewan, 44 Innovation Boulevard SK S7N 2V3, \\ Saskatoon, Canada \\ ${ }^{\S}$ Kavli Institute of Nanoscience, Delft University of Technology, Lorentzweg 1, 2628 CJ Delft, Netherlands \\ ${ }$ Research Centre for Catalysts, Albemarle Catalysts Company B.V., 1030 BE Amsterdam, Netherlands \\ ${ }^{\perp}$ Shell Projects \& Technology/Criterion Catalysts, Grasweg 31, $1031 \mathrm{HW}$ Amsterdam, Netherlands
}

ABSTRACT: We visualize the elemental zoning in an alumina-supported cobalt molybdenum sulfide (CoMoS) catalyst with scanning transmission X-ray microscopy (STXM). We use the Canadian Light Source beamline 10-ID's (SM) unique combination of soft X-ray and tender X-ray STXM to determine the spatial variation of $\mathrm{Co}, \mathrm{Al}, \mathrm{Mo}$, and $\mathrm{S}$ species. The results clearly show the correlation between cobalt and molybdenum and the anticorrelation between cobalt and alumina, confirming that Co is closely associated with the $\mathrm{MoS}_{2}$ phase. The tender X-ray STXM images show that the fresh catalyst particle contains a $50 \mathrm{~nm}$ ring of molybdenum oxide encapsulating the supported $\mathrm{MoS}_{2}$ phase. After the reduction at $200{ }^{\circ} \mathrm{C}$ with $\mathrm{H}_{2}$, this oxide rim disappears and a uniform $\mathrm{MoS}_{2}$ distribution is found. Upon oxidation at $400{ }^{\circ} \mathrm{C}$, the sulfur disappears from the catalyst sample and molybdenum is oxidized from a $\mathrm{Mo}^{\mathrm{IV}}$ sulfide to a mainly tetrahedral $\mathrm{Mo}^{\mathrm{VI}}$ oxide, while cobalt keeps its divalent nature and changes from a $\mathrm{Co}^{\mathrm{II}}$ sulfide to a $\mathrm{Co}^{\mathrm{II}}$ oxide.

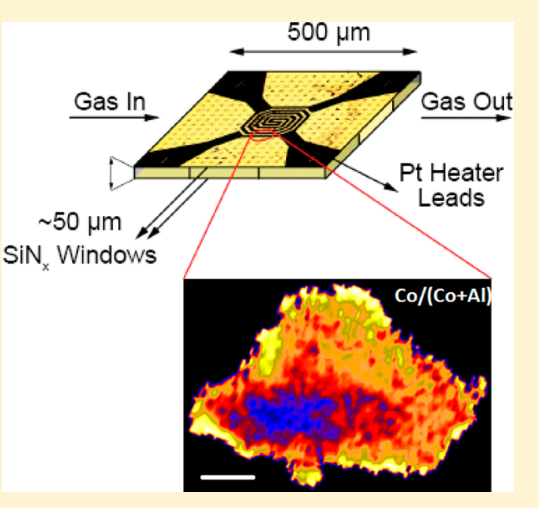

\section{INTRODUCTION}

Hydrodesulfurization (HDS) catalysts are receiving continuous attention because of their important function of removing sulfur from transportation fuels. For the past decades these catalysts have been applied in the petroleum industry for this vital role. Because of stringent environmental regulations in the United States and Europe, where the sulfur content in fuels, especially diesel fuels, must be lowered to below $10 \mathrm{ppm}$, more effective catalyst materials must be developed that efficiently lower the sulfur content to the desired levels. ${ }^{1,2}$ Similar catalyst systems also play an important role in other catalytic reactions, such as hydro-denitrogenation and hydro-deoxygenation. In this paper the classic alumina-supported Co-promoted molybdenum sulfides HDS catalysts is studied. ${ }^{3-6}$

In the HDS reaction, sulfur is cleaved from organic molecules, such as thiophenes and (di)benzothiophenes. There is debate in the literature concerning the nature of the active sites in CoMo- and NiMo-based hydroprocessing catalysts. Authors agree that molybdenum sulfide $\left(\mathrm{MoS}_{2}\right)$ slabs are a main constituent of the active phase, but promotion by nickel or cobalt is required to obtain highly active catalysts. The role and location of the promoter atoms is a subject of debate. $^{7-12}$ One of the leading theories places the promoter atoms at the outer edge of the $\mathrm{MoS}_{2}$ slabs, where they help create specific conditions beneficial to hydrogenation (electronic structure) or direct desulfurization (sulfur defects). Although the proximity of promoter and molybdenum structures can be demonstrated for example by extended Xray absorption fine structure (EXAFS) analysis, also separate clusters of cobalt sulfides $\left(\mathrm{Co}_{9} \mathrm{~S}_{8}\right)$ are reported. It is thus of interest to study the local distribution of the constituents as well as their local chemistry, coordination, and oxidation state. Although oxidation of the catalyst material by air does not normally occur under industrial conditions, it may occur under laboratory conditions (e.g., sample transfer).

The X-ray absorption near-edge structure (XANES) is specific for the chemical nature. The aluminum $\mathrm{K}$ and sulfur $\mathrm{K}$ edge can be described as transitions from the $1 \mathrm{~s}$ core state to empty states of $\mathrm{p}$-character, and the molybdenum and cobalt $\mathrm{L}_{3}$ edges as transitions from the $2 \mathrm{p}_{3 / 2}$ core state to empty states of mainly 3d-character. The $\mathrm{Al}, \mathrm{S}$, and Mo edges can be well described with a single-particle transition, while the Co edge is strongly affected by multiplet effects. ${ }^{13,14}$ Scanning transmission

Received: October 28, 2014

Revised: January 13, 2015

Published: January 13, 2015 


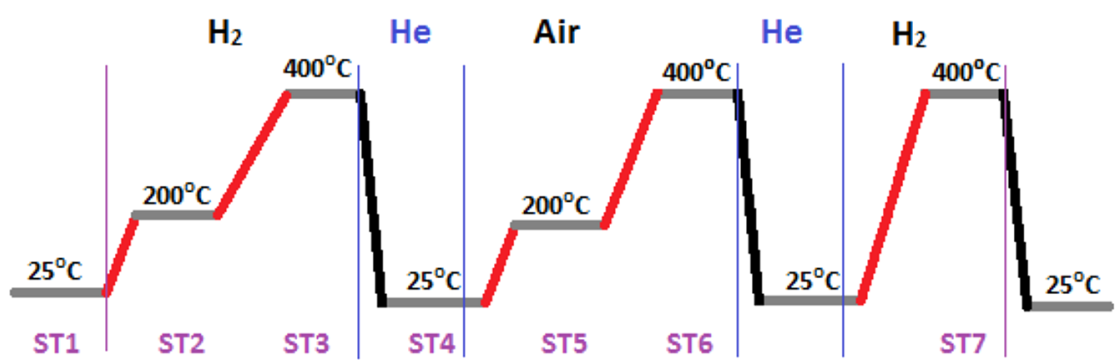

Figure 1. Schematic showing the consecutive steps during the in situ STXM measurements. The time needed for each stage (ST) is $2 \mathrm{~h}$. The sample is first measured in its initial state (fresh) after exposure to air under helium flow (ST1). Following this, the reactor was flowed with $1 \mathrm{~mL} / \mathrm{min}$ of $\mathrm{H}_{2}$ gas and heated in the first stage to $200{ }^{\circ} \mathrm{C}$ (ST2) and subsequently to $400{ }^{\circ} \mathrm{C}$ with a ramp of $20^{\circ} \mathrm{C} / \mathrm{min}$ (ST3). After the reduction step, the sample was cooled under helium flow (ST4). The sample was then purged with air $(1 \mathrm{~mL} / \mathrm{min})$ and heated to $200{ }^{\circ} \mathrm{C}(\mathrm{ST} 5)$ and $400{ }^{\circ} \mathrm{C}(\mathrm{ST} 6)$. After the sample was cooled to room temperature and flowed with helium, the sample was again heated under $\mathrm{H}_{2}$ flow where the last stack was recorded (ST7).

X-ray microscopy (STXM) is able to measure XANES spectra at a spatial resolution of $\sim 25 \mathrm{~nm}$.

\section{EXPERIMENTAL SECTION}

2.1. Materials and in Situ Conditions. A coimpregnated $\mathrm{CoMo} / \mathrm{Al}_{2} \mathrm{O}_{3}$ (6 atm. wt \% Co, 12 atm. wt \% Mo) sample was prepared by incipient wetness impregnation of $Y-\mathrm{Al}_{2} \mathrm{O}_{3}$ powder (BASF Al-4184; surface area, $250 \mathrm{~m}^{2} / \mathrm{g}$; pore volume, $0.70 \mathrm{~mL} /$ $\mathrm{g}$ ) with a solution of ammonium heptamolybdate hexahydrate $\left(\left(\mathrm{NH}_{4}\right)_{6} \mathrm{Mo}_{7} \mathrm{O}_{24} \cdot 6 \mathrm{H}_{2} \mathrm{O}\right.$, Sigma-Aldrich, $99.98 \%$ trace metals basis) and cobalt nitrate hexahydrate $\left(\mathrm{Co}\left(\mathrm{NO}_{3}\right)_{2} \cdot 6 \mathrm{H}_{2} \mathrm{O}\right.$, SigmaAldrich, $99.999 \%$ trace metals basis). Subsequently, the sample was dried under static air at $60{ }^{\circ} \mathrm{C}$ for $16 \mathrm{~h}$. To convert the impregnated cobalt nitrate and ammonium heptamolybdate to their respective metal oxides the sample was calcined in air at $450{ }^{\circ} \mathrm{C}$ for $16 \mathrm{~h}$ (sample code, CoMoS-3). The sample was sulfurized with a $10 \% \mathrm{H}_{2} \mathrm{~S} / \mathrm{H}_{2}$ mixture gas. Here, the sample was heated to $450{ }^{\circ} \mathrm{C}$ and kept at this temperature for $4 \mathrm{~h}$. For the in situ reduction, $99.998 \%$ pure $\mathrm{H}_{2}$ gas (Linde Canada) and compressed air 99.99\% (Linde Canada) was used. Between the consecutive oxidation and reduction steps of the in situ reaction, helium (99.999\%, $\mathrm{HiQ}$ Linde Canada) was flowed through the reactor for $30 \mathrm{~min}$. Prior to the measurement, the STXM chamber was evacuated for $10 \mathrm{~min}$ and subsequently filled with helium (99.99\% grade, Linde Canada) to obtain $1 / 6$ atmospheric pressure.

2.2. STXM Experiments. STXM was carried out at the spectromicroscopy (SM) beamline 10ID-1 of the Canadian Light Source (CLS). The beamline provides linear polarized light between 130 and $2700 \mathrm{eV}$. Using Fresnel zone plates, monochromatic soft X-rays are used with a probe size of $25 \mathrm{~nm}$. The sample is raster-scanned with synchronized detection of transmitted X-rays to create elemental maps.

We have measured the cobalt $\mathrm{L}_{3}$ edge at $780 \mathrm{eV}$, the aluminum K edge at $1560 \mathrm{eV}$, the sulfur $\mathrm{K}$ edge at $2471 \mathrm{eV}$, and the molybdenum $\mathrm{L}_{3}$ edge at $2522.5 \mathrm{eV}$. The energy resolution of the beamline is $E / \Delta E=3000-10000$, and the flux at $\mathrm{Co}_{3}$ edge $(780 \mathrm{eV})$ is $>10^{6} \mathrm{ph} / \mathrm{s}$. At the $\mathrm{Mo} \mathrm{L}_{3}$ edge $(2520 \mathrm{eV})$, the flux dramatically decreases to approximately $10^{3} \mathrm{ph} / \mathrm{s}$. For a measurement of the $\mathrm{Co}_{3}$ edge at $780 \mathrm{eV}$, a relatively thin catalyst particle is needed, whereas at the $\mathrm{Mo} \mathrm{L}_{3}$ edge at 2500 $\mathrm{eV}$, a thicker particle is more suitable for sufficient absorption. This made it difficult to find convenient nanoparticles and structures that are positioned well inside the nanoreactor.

The nanoreactor consists of a reactor chamber of $\sim 500 \times$ $500 \times 50 \mu \mathrm{m}^{3}$, which was supplied with gases by micrometer- sized gas channels and fitted with a resistive Pt heater element, allowing heating up to $400{ }^{\circ} \mathrm{C}$. The transmission through the $20 \mathrm{~nm} \mathrm{Si}_{3} \mathrm{~N}_{4}$ windows, the $50 \mu \mathrm{m} 1$ bar gas atmosphere, and a $100-5000 \mathrm{~nm}$ thick sample allows for excellent in situ STXMXAS experiments. ${ }^{15}$ It is noted that the nanoreactor contains 5 $\times 5 \mu \mathrm{m}^{2}$ areas that have a window thickness of $10 \mathrm{~nm}$, but at the cobalt $\mathrm{L}_{3}$ edge $(778 \mathrm{eV})$ and especially at the sulfur $\mathrm{K}$ edge and Mo L edges $(\sim 2.5 \mathrm{keV})$, the STXM experiments are also possible through the $200 \mathrm{~nm}$ thick nanoreactor walls.

The plan of the in situ reaction is shown in detail in Figure 1. The $\mathrm{CoMoS} / \mathrm{Al}_{2} \mathrm{O}_{3}$ was first measured in the state as it was introduced in the beamline. Then, three reaction steps were performed: (1) the reduction to create a uniform $\mathrm{CoMoS}$ sample with $\mathrm{H}_{2},(2)$ the oxidation with air, and (3) a second reduction with $\mathrm{H}_{2}$. All reactions were performed to a temperature up to $400{ }^{\circ} \mathrm{C}$, as shown in Figure 1. This nanoreactor has been used previously for the measurement of other catalytic reactions under in situ STXM conditions. ${ }^{16-18}$

Throughout the experiment, we have measured a number of particles that were present inside the nanoreactor. In this study we focus on one nanoparticle that has a size of approximately 9 $\times 5 \mu \mathrm{m}$. Particles that are smaller are problematic in the sense that the molybdenum $\mathrm{L}_{3}$ and $\mathrm{S} \mathrm{K}$ edges had a low signal-tonoise ratio and could not be used. The particles or aggregates with a larger size had problems due to saturation effects. The 9 $\times 5 \mu \mathrm{m}(x, y)$ particle that was used in this study had the "ideal size" to allow the measurements of the cobalt L edge at $780 \mathrm{eV}$ and also the Mo L edge at $\sim 2500 \mathrm{eV}$. The nanoreactor possesses temperature gradients over its internal structure, with higher temperatures at the center of the heater inside the nanoreactor. ${ }^{18,19}$ We have used the calibration curves for the temperature gradient to set the required temperature at the position of the nanoparticle of interest. The other nanoparticles inside the nanoreactor were at a (slightly) different temperature during the treatments. All measurements shown in the manuscript were measured in their completely reduced state or completely oxidized state. We have checked for a number of other particles that this complete reduction respectively oxidation was reached. The spectral shapes of the sulfur $\mathrm{K}$ edge and the molybdenum L edge did not change over time, confirming that under the conditions used, the X-ray beam did not influence the electronic structure (valence) of the system.

XANES spectra and chemical maps were obtained from STXM image sequence (stack) scans. ${ }^{20}$ For this study, S K edge and $\mathrm{Mo}_{3}$ edge combined image stacks were recorded from 2460 to $2560 \mathrm{eV}$ with an energy step of $0.2 \mathrm{eV}$ around the 
XANES peaks and energy steps between 0.5 and $1.0 \mathrm{eV}$ in the pre-edge and the continuum. The stacks for $\mathrm{Co}$ and $\mathrm{Al}$ were collected at the energy range of 775-785 eV and 1550-1600 $\mathrm{eV}$, respectively. The energy has been calibrated with references from the literature for $\mathrm{MoS}_{2}{ }^{9}$ and $\mathrm{CoO} .{ }^{21}$ We did not apply any background correction. To map the $10 \mu \mathrm{m}$ catalyst particle, we use a stack dimension of $15 \times 10 \mu \mathrm{m}$ that was raster scanned with $75 \times 50$ points, implying a pixel-pixel distance of $200 \mathrm{~nm}$. The image pixel size was $25 \mathrm{~nm}$, and dwell time was $2 \mathrm{~ms}$ per pixel.

The X-ray beam was focused on the sample plane using a Fresnel zone plate $(\mathrm{ZP})$, where the beam is selected using an order-sorting aperture (OSA) with a $50 \mathrm{~mm}$ pinhole. The OSA allows only first-order diffracted light to pass. Sequences of spectral elemental images (stacks) were measured by recording images over a range of photon energies. Data analysis was performed using aXis2000. After the image sequence of a stack was aligned, spectra of the particle were extracted. In addition, stacks were fit to reference spectra of the components using linear regression. The gases were dosed with mass flow controllers (Bronkhorst). During the in situ STXM experiments a flow of $1 \mathrm{~mL} / \mathrm{min}$ was used for all the utilized gases.

At the $\mathrm{Mo} \mathrm{L}_{3}$ edge $(2500 \mathrm{eV})$, approximately $10 \%$ of the $\mathrm{X}$ rays are transmitted, whereas at the cobalt $\mathrm{L}$ edge $(780 \mathrm{eV})$, only $0.01 \%$ is transmitted. That a signal is measurable is only due to the fact that the beamline intensity at $780 \mathrm{eV}$ is very high $\left(10^{11} \mathrm{ph} / \mathrm{s}\right)$, which allows one to lose $99.99 \%$ of the intensity and still measure a detectable signal. At $2500 \mathrm{eV}$ the beamline intensity is much lower, $\left(10^{4} \mathrm{ph} / \mathrm{s}\right)$, but now $90 \%$ of the intensity is transmitted. Elemental maps can be generated from the raster-scanned XANES spectra. From these maps the distribution of the measured elements can be obtained and elemental maps can be generated. The images are obtained by subtracting the pre-edge image from the image taken at the respective energies as indicated in Table 1.

Table 1. Molybdenum, Sulfur, Aluminum, and Cobalt (Pre) Edge Energies at Which the Images Have Been Measured

\begin{tabular}{lcc} 
& $\begin{array}{c}\text { pre-edge energy } \\
(\mathrm{eV})\end{array}$ & $\begin{array}{c}\text { edge energy } \\
(\mathrm{eV})\end{array}$ \\
Mo $\mathrm{L}_{3}$ edge (sulfide sample, ST3) & 2520.0 & 2529.5 \\
Mo L ${ }_{3}$ edge (oxide sample, ST6) & 2516 & 2522.5 \\
$\mathrm{~S} \mathrm{~K}$ edge & 2462.5 & 2470.4 \\
$\mathrm{Al} \mathrm{K}$ edge & 1560.0 & 1570.3 \\
$\mathrm{Co} \mathrm{L}_{3}$ edge & 776.5 & 778.5 \\
\hline
\end{tabular}

\section{RESULTS}

3.1. XANES Spectra. Under flow of $\mathrm{H}_{2}$, the sample was heated to $400{ }^{\circ} \mathrm{C}$, where XANES spectra from the sulfur $\mathrm{K}$ $(2470 \mathrm{eV})$ and $\mathrm{Mo} \mathrm{L}_{3}$ edge $(2520 \mathrm{eV})$ have been measured. Because of the close proximity of their excitation energies they are simultaneously measured in a single stack. This makes the imaging easier as the resulting spectral elemental maps are directly aligned. The XANES spectra shown below have been added from the entire nanoparticle. Because of the low flux at the $\mathrm{Mo} \mathrm{L}_{3}$ and $\mathrm{S} \mathrm{K}$ edges, the data quality of smaller regions was not good. As far as the data quality allowed, we could not detect any spatial difference in the spectral line shape.

The sulfur $\mathrm{K}$ edge spectra of the reduced sample and that of $\mathrm{CoS}, \mathrm{CoS}_{2}, \mathrm{Co}_{9} \mathrm{~S}_{8}$, and $\mathrm{MoS}_{2}$ reference samples ${ }^{9,22}$ are shown in Figure 2. Given the data quality and the similarity of the

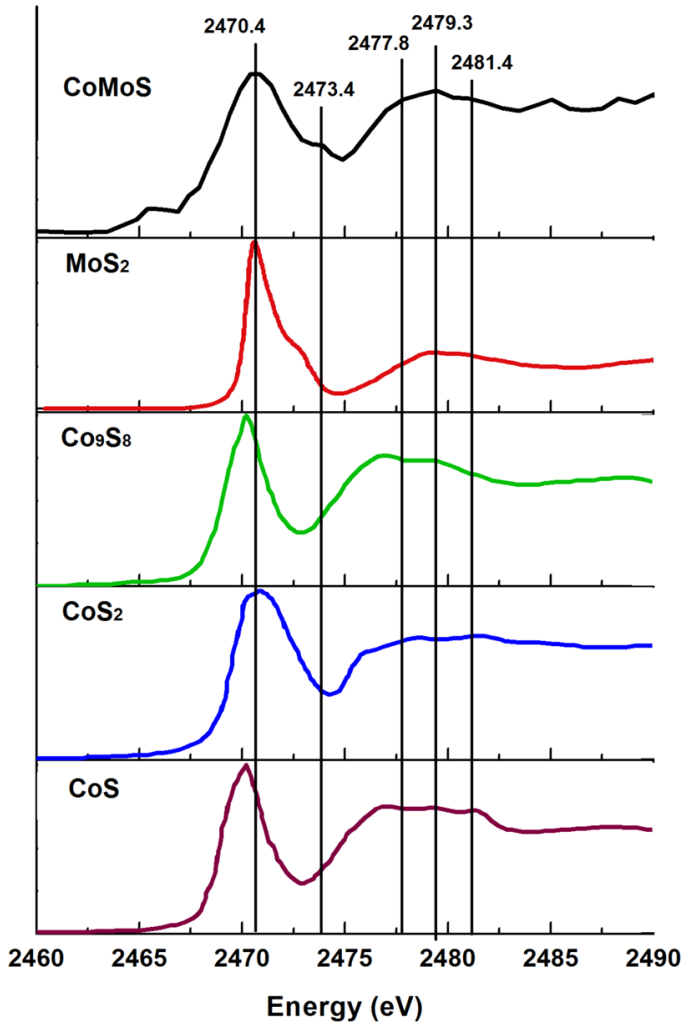

Figure 2. Sulfur $\mathrm{K}$ edge spectrum of active CoMoS sample (top) collected at ST3, in comparison with reference spectra, from bottom to top, $\mathrm{CoS}, \mathrm{CoS}_{2}, \mathrm{Co}_{9} \mathrm{~S}_{8}$, and $\mathrm{MoS}_{2}$ digitized from the literature. ${ }^{10,22}$

cobalt and molybdenum sulfide spectra, it is not possible to arrive at a firm conclusion regarding the nature of sulfur in our CoMoS sample. The best simulation of the CoMoS spectrum is from a combination of $\mathrm{CoS} / \mathrm{CoS}_{2}$ and $\mathrm{MoS}_{2}$ spectra, but the presence of $\mathrm{Co}_{9} \mathrm{~S}_{8}$ cannot be ruled out.

The molybdenum $\mathrm{L}_{3}$ absorption at $2522.9 \mathrm{eV}$ is equivalent to the $\mathrm{MoS}_{2}$ reference spectrum. ${ }^{9}$ Following the STXM measurement, the sample was cooled to room temperature and kept under dynamic helium flow.

Then, under a flow of air, the temperature in the STXM cell was gradually increased to 200 and $400{ }^{\circ} \mathrm{C}$ and in situ stacks were recorded to study the sulfurized phase of the sample. At $400{ }^{\circ} \mathrm{C}$ the molybdenum $\mathrm{L}_{3}$ edge is shifted toward higher energy $(2528.2$ and $2529.5 \mathrm{eV})$ and the spectral shape has also changed in agreement with the oxidation from $\mathrm{Mo}^{\mathrm{IV}}$ to $\mathrm{Mo}^{\mathrm{VI}}$. ${ }^{10,23-25}$ The double-peak structure is due to crystal field splitting, where in octahedral $\mathrm{Mo}^{\mathrm{VI}}$ species such as $\mathrm{MoO}_{3}$ the first peak has more intensity and in tetrahedral species such as $\mathrm{MoO}_{4}{ }^{2-}$ the second peak has more intensity. Bare showed the gradual change from tetrahedral to octahedral species. ${ }^{24}$ In Figure 3 it can be seen that the second peak has more intensity, and we conclude that the spectra measured in the CoMoS sample contain molybdenum in majority in a tetrahedral surrounding. The splitting between the two peaks is approximately $1.5 \mathrm{eV}$, which also indicates a tetrahedral crystal field surrounding. ${ }^{25}$

In Figure 4, the cobalt $\mathrm{L}_{3}$ spectrum of the CoMoS sample is given in the sulfided ST3 phase and in the oxide ST7 phase. The CoMoS spectrum in the oxide phase is equivalent to that of CoO. ${ }^{12,26}$ This indicates that cobalt is reduced to divalent cobalt and no $\mathrm{Co}^{3+}$ can be detected. Trivalent cobalt would 


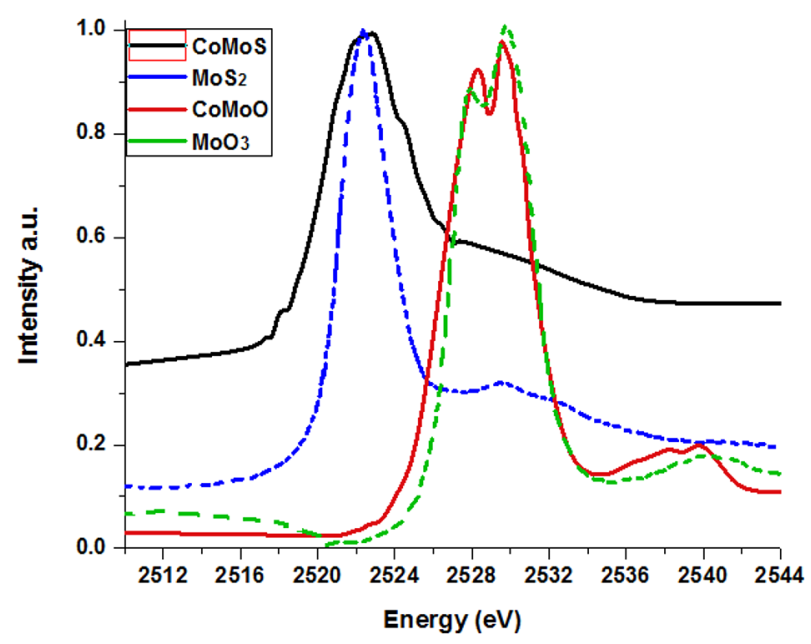

Figure 3. (A) Mo $\mathrm{L}_{3}$ edge of the sulfided state ST3 (black) and after the oxidation step ST6 (red) at $200{ }^{\circ} \mathrm{C}$. The spectra are compared with reference spectra for $\mathrm{MoS}_{2}$ (dotted, blue) and $\mathrm{MoO}_{3}\left(\mathrm{Mo}^{\mathrm{VI}}\right)$ species (dotted, green), both digitized from the literature., ${ }^{9,10}$

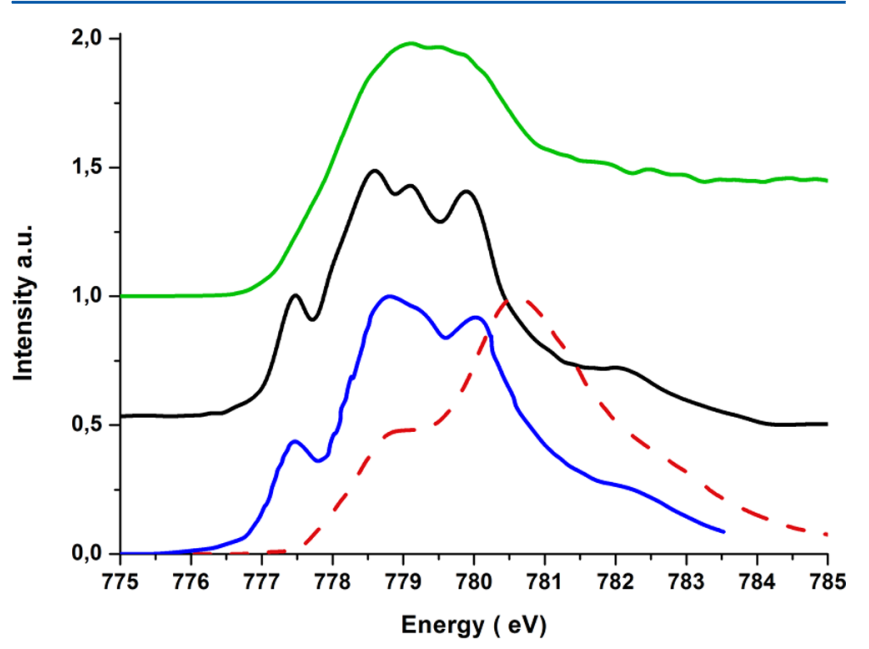

Figure 4. Cobalt $\mathrm{L}_{3}$ edges of sulfided CoMoS-3 after the reduction step at ST3 (top, green) and the spectrum after oxidation at ST7 (middle, black) in comparison with reference spectra of $\mathrm{CoO}$ (blue) and $\mathrm{Co}_{3} \mathrm{O}_{4}$ (red, dashed) digitized from the literature. ${ }^{12}$

show as extra intensity at the high-energy side, as shown for the $\mathrm{Co}_{3} \mathrm{O}_{4}$ reference spectrum.

The aluminum $\mathrm{K}$ edge is shown in Figure 5. The spectrum observed is identical to published spectra of $r-\mathrm{Al}_{2} \mathrm{O}_{3}{ }^{11,27} \mathrm{We}$ observed no change in the aluminum $\mathrm{K}$ edge throughout the experiment indicating that there is no detectable change in the aluminum coordination and valence.

3.2. In Situ STXM Maps. The spectral elemental maps of molybdenum and sulfur are shown in Figure 6. We have considered the quantification of the element maps to quantitative thickness or mass absorption but came to the conclusion that there are too many uncertainties to yield a reliable result. The unknowns are (1) the ratio between Codoped $\mathrm{MoS}_{2}$ and $\mathrm{Al}_{2} \mathrm{O}_{3}$ at every pixel and (2) the exact nature and density of Co-doped $\mathrm{MoS}_{2}$. As a result, the (column averaged) density at every pixel is unknown, implying that we cannot calculate the mass absorption and the thickness. To be more precise, the attenuation coefficient $\mu=x 1^{*} \mu 1+x 2^{*} \mu 2$, with $\mathrm{x}$ the amount and $\mu$ the attenuation coefficient for $\mathrm{Al}_{2} \mathrm{O}_{3}$ and $\mathrm{MoS}_{2}$, respectively, and all four parameters are unknown.

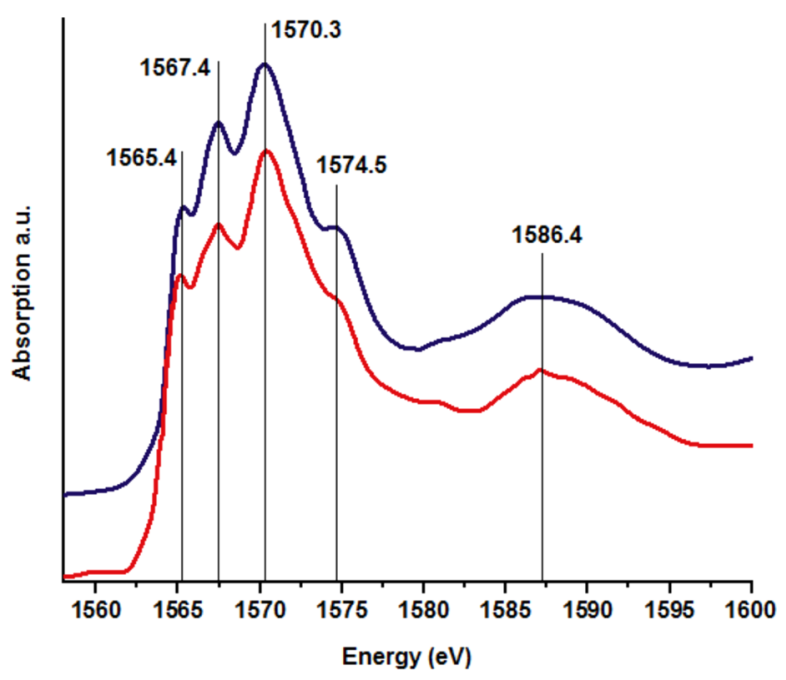

Figure 5. Aluminum $\mathrm{K}$ edge (black, vertical offset) and the $r-\mathrm{Al}_{2} \mathrm{O}_{3}$ reference digitized from the literature (red). ${ }^{27}$

As a result, we have chosen to show only the optical density (OD). In addition, we have chosen the ratio $\mathrm{Mo} /(\mathrm{Mo}+\mathrm{S})$ to create a number between zero (only sulfur, no Mo) and the OD-ratio (only Mo, no S). Such analysis does not provide quantitative information on the amount of $S$ and Mo, but only information on the spatial variation of the relative amounts. Figure 6 is divided in six vertical panels indicating the six different phases of the in situ reaction. Here, the top panel corresponds to the initial situation (fresh sample) before the reduction step, showing from left to right the molybdenum $\mathrm{L}_{3}$ edge, the sulfur $\mathrm{K}$ edge, and the ratio map of $\mathrm{Mo} /(\mathrm{Mo}+\mathrm{S})$ to the right. From the figure we can conclude that after reducing the sample at ST2 and ST3 both the molybdenum and sulfur regain their high dispersion over the complete particle. This is believed to be due to the surface mobility of the sulfides under hydrogen atmosphere and elevated temperatures. However, by looking at the ratio map of the fresh sample, we can distinguish $\mathrm{Mo} /(\mathrm{Mo}+\mathrm{S})$ ratios close to 1.0 near the outer surface. In other words, the outside edge of the catalyst particle contains essentially no sulfur, indicating that this region of the sample has been oxidized to molybdenum oxide after exposure to air under ambient conditions. It can be concluded that the CoMoS sample is sensitive to oxidation upon exposing it to air. Even though the sample was kept at the room temperature and exposed for only a short time, an oxygen rim can be seen.

The second and third panel show the situation after the reduction at 200 and $400{ }^{\circ} \mathrm{C}$, respectively. Both molybdenum and sulfur are dispersed over the whole particle. The sulfurpoor rim around the particle has disappeared. After the oxidation at $200{ }^{\circ} \mathrm{C}$ and following this at $400{ }^{\circ} \mathrm{C}$, the $\mathrm{Mo} /$ (Mo $+\mathrm{S}$ ) ratio is almost equal to 1.0 over the whole particle (Figure $6 \mathrm{~J}-\mathrm{L}, \mathrm{M}-\mathrm{O})$. There is no sulfur absorption any more, as is evident from the sulfur spectral elemental map. From this we can conclude that the sulfur in the sample is replaced by oxygen by raising the temperature to $200{ }^{\circ} \mathrm{C}$. In the final step of the in situ reaction the sample was exposed to a second reduction step with temperature up to $400{ }^{\circ} \mathrm{C}$. The result is shown in the panels $\mathrm{P}-\mathrm{R}$ of Figure 6. Because sulfur absorption remains absent, the $\mathrm{Mo} /(\mathrm{Mo}+\mathrm{S})$ ratio remains around 1.0 over the whole catalyst particle.

Figure 7 shows the elemental maps of $\mathrm{Al}, \mathrm{Mo}$, and Co after oxidation (ST7), where all maps have been shown the OD 


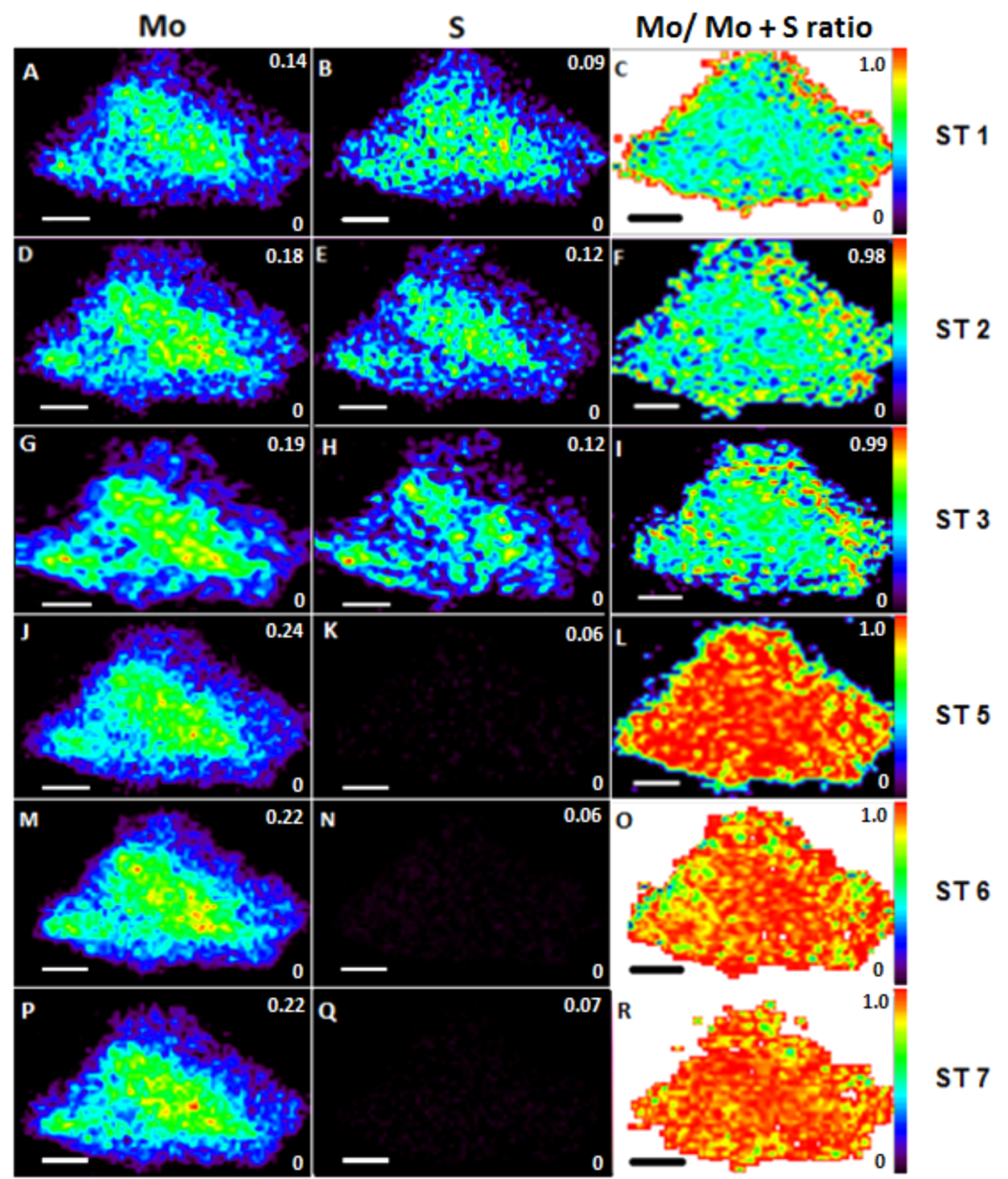

Figure 6. STXM spectral elemental maps of the $\mathrm{Mo} \mathrm{L}_{3}$ edge in the left column (images A, D, G, J, M, and P) and the S K edge in the middle column (images $\mathrm{B}, \mathrm{E}, \mathrm{H}, \mathrm{K}, \mathrm{N}$, and $\mathrm{Q}$ ). The right column shows the $\mathrm{Mo} /(\mathrm{Mo}+\mathrm{S}$ ) ratio, where red indicates 1.0 (pure Mo) and blue-green relates to $\sim 0.33$ $\left(\mathrm{MoS}_{2}\right)$. The panels show the spectral maps during different stages of the in situ reaction, ST1 to ST7, as indicated on the right (cf. Figure 1). The scale bar indicates $2 \mu \mathrm{m}$.
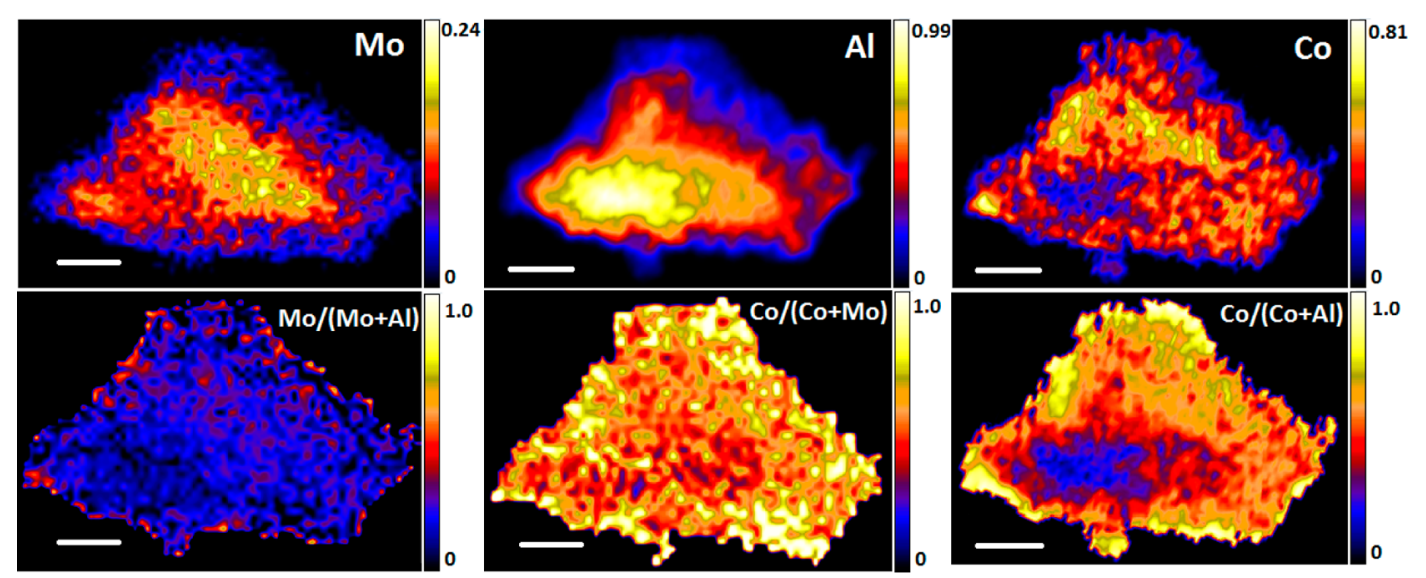

Figure 7. STXM spectral images of the $\mathrm{Al} \mathrm{K}$ edge, $\mathrm{Mo} \mathrm{L}_{3}$ edge, and $\mathrm{Co}_{3}$ edge at $\mathrm{ST} 7$. The scale bar values indicate the maximum $\mathrm{OD}$ values. The ratio maps of $\mathrm{Mo} /(\mathrm{Mo}+\mathrm{Al}), \mathrm{Co} /(\mathrm{Co}+\mathrm{Mo})$, and $\mathrm{Co} /(\mathrm{Co}+\mathrm{Al})$ are shown in the bottom row. For the ratio maps, areas in white have the ratio close to 1.0 whereas those in dark blue have a ratio close to 0.0 . The scale bar indicates $2 \mu \mathrm{m}$.

values obtained after subtracting the value of the pre-edge from the respective edge values. In other words, we will analyze only the spatial variations of the relative occurrence. As indicated above we did not have enough information to normalize the 
intensities on an absolute scale. The images were obtained by first aligning the two spectral elemental maps followed by creating a mask over the particle. The mask was created based on an applied threshold of $5 \%$ of maximum intensity of the absorption. From Figure 7 the ratios of $\mathrm{Co} /(\mathrm{Co}+\mathrm{Al})$ and $\mathrm{Mo} /$ $(\mathrm{Mo}+\mathrm{Al})$ are lowest in the $\mathrm{Al}$-rich region in the left-center. This indicates a variation of the (Co)Mo-oxide phase over the sample on a micrometer range. In addition, there are indications of a Co-rich and Mo-rich rim around the sample. The bottom left part of the particle has the highest $\mathrm{Al}$ intensity and the lowest Co intensity, as is directly evidenced by the $\mathrm{Co} /$ $(\mathrm{Co}+\mathrm{Al})$ ratio map. The $\mathrm{Co} /(\mathrm{Co}+\mathrm{Mo})$ ratio varies over the sample, where the cobalt content is lower in the middle of the sample, in the region where the $\mathrm{r}-\mathrm{Al}_{2} \mathrm{O}_{3}$ phase dominates.

\section{DISCUSSION}

4.1. Implications of the XANES Analysis. The XANES analysis gives a clear picture of the behavior of the CoMoS/ $\mathrm{Al}_{2} \mathrm{O}_{3}$ sample during reduction and oxidation. In the sulfided phases, cobalt is divalent and molybdenum appears in the $\mathrm{Mo}^{\mathrm{IV}}$ form, with a spectral shape identical to that of $\mathrm{MoS}_{2}$. From the sulfur $\mathrm{K}$ edge, we cannot distinguish if the spectral shape is dominated by $\mathrm{CoS}, \mathrm{CoS}_{2}, \mathrm{Co}_{9} \mathrm{~S}_{8}$, or $\mathrm{MoS}_{2}$. The Mo $\mathrm{L}_{3}$ edge indicates the presence of $\mathrm{MoS}_{2}$, but regarding the cobalt phase we cannot make a conclusion based on the XANES data. It is also possible that cobalt appears in the form of CoMoS, $\mathrm{CoAl}_{2} \mathrm{O}_{4}$, and bulk $\mathrm{Co}_{9} \mathrm{~S}_{8}$, which is expected for the fresh sample at ST2 and ST3.

After the oxidation step, the aluminum spectral shape resembles that of the $\mathrm{r}-\mathrm{Al}_{2} \mathrm{O}_{3}$ reference compound; in other words, the aluminum state was not affected under all conditions. Cobalt is changed from a sulfide to an oxide, as evidenced by the sharp cobalt $\mathrm{L}_{3}$ features. The valence of cobalt remains the same though; essentially, divalent cobalt-sulfide is changed into $\mathrm{CoO}$, or in any case into an octahedral high-spin $\mathrm{Co}^{\mathrm{II}}$ oxide. At the same time molybdenum changes its valence from $\mathrm{Mo}^{\mathrm{IV}}$ into $\mathrm{Mo}^{\mathrm{VI}}$. The fine structure of the $\mathrm{Mo} \mathrm{L}_{3}$ edge indicates that not $\mathrm{MoO}_{3}$ but rather a tetrahedral $\mathrm{Mo}^{\mathrm{VI}}$ oxide species is formed.

4.2. Discussion on Distribution of Elements. The initial sample contains an oxide rim around the sample. This rim disappears under reduction that contains a homogeneous $\mathrm{CoMoS}$ phase. Under oxidation the sulfide phase is turned into a homogeneous oxide phase. We note that because of the very low flux at $2.5 \mathrm{keV}$, the data quality did not allow the study of spatial variations in the chemical information. The comparison of the $\mathrm{Al}, \mathrm{Co}$, and Mo maps indicates that $\mathrm{Co}$ and Mo appear to be correlated. The distribution of Co and Mo is in antiphase with the distribution of $\mathrm{Al}$; in other words, where there is much alumina there is little CoMoS. These observations indicate that the CoMoS distribution is rather homogeneous over the micron scale with minor variations in the thicker parts (bottom left) of the alumina support. Cobalt and molybdenum are very well mixed into a homogeneous phase with only a minor increase of cobalt and molybdenum toward the outside of the particle.

\section{CONCLUDING REMARKS}

The sequence of reduction with $\mathrm{H}_{2}$, oxidation with air, and regeneration with $\mathrm{H}_{2}$ on a single $\mathrm{CoMoS} / \mathrm{Al}_{2} \mathrm{O}_{3} \mathrm{HDS}$ catalyst particle was measured with in situ STXM at the cobalt $\mathrm{L}_{3}$, aluminum $\mathrm{K}$, sulfur $\mathrm{K}$, and molybdenum $\mathrm{L}_{3}$ edge. For the first time, the tender X-ray edges of molybdenum and sulfur were measured with STXM under in situ reduction and oxidation conditions. The sulfurized phase was oxidized at the edges, and a $50 \mathrm{~nm}$ oxide ring surrounded the catalyst particle. Under oxidation conditions $\mathrm{MoS}_{2}$ species were converted to a tetrahedral $\mathrm{Mo}^{\mathrm{VI}}$ oxide species, while cobalt remained divalent. Sulfur has reacted with oxygen to form sulfur oxide species $\left(\mathrm{SO}_{x}\right)$, and at $200{ }^{\circ} \mathrm{C}$, the sample was fully oxidized and the $\mathrm{Mo} /(\mathrm{Mo}+\mathrm{S})$ ratio was equal to 1.0. STXM enabled us to extract information about the oxidation state and distribution of the different elements under in situ conditions. The intensity of the cobalt and molybdenum images are correlated, and they are anticorrelated with aluminum, showing the intrinsic combination of $\mathrm{Co}$ and Mo in their sulfide phase. This correlation remained after oxidation.

The prospects of this technique are its application to study the in situ sulfurization of the oxide precursor of the CoMoS HDS catalyst. The most interesting process to study is the in situ hydrodesulfurization process of the thiophene and its derivatives to investigate the promotional effect of cobalt upon its addition to $\mathrm{MoS}_{2}$. This knowledge is obtained by measuring changes in the oxidation state and the coordination of cobalt and molybdenum.

\section{AUTHOR INFORMATION}

\section{Notes}

The authors declare no competing financial interest.

\section{ACKNOWLEDGMENTS}

This project has been performed within the framework of a STW-Nano project. The authors gratefully acknowledge the support of the joint sponsors: Albemarle Catalysts B.V., Shell Chemicals, BASF, and Dow Chemicals. The authors thank the beamline staff of beamline 10ID-1 (SM) at the CLS for beamtime and support. Furthermore, Korneel Cats, Hendrik van der Bij, and Ramon Oord of Utrecht University are kindly thanked for their help during the STXM measurements.

\section{REFERENCES}

(1) Song, C.; Ma, X. New Design Approaches to Ultra-clean Diesel Fuels by Deep Desulfurization and Deep Dearomatization. Appl. Catal., B 2003, 41, 207-238.

(2) Eijsbouts, S.; Battiston, A. A.; van Leerdam, G. C. Life Cycle of Hydroprocessing Catalysts and Total Catalyst Management. Catal. Today 2008, 130, 361-373.

(3) Topsøe, H.; Clausen, B. S. Active Sites and Support Effects in Hydrodesulfurization Catalysts. Appl. Catal. 1986, 25, 273-293.

(4) Moon, S. J.; Ihm, S. K. Characteristics of Bimetallic Cobalt and Molybdenum Catalysts Supported on Activated Carbon or Alumina In. Korean J. Chem. Eng. 1994, 11, 111-118.

(5) Kim, K. L.; Choi, K. S. Kinetics of Hydrodesulfurization of Dibenzothiophene over $\mathrm{NiO}-\mathrm{MoO}_{3} / \mathrm{Y}-\mathrm{Al}_{2} \mathrm{O}_{3}$ Catalyst. Korean J. Chem. Eng. 1988, 5, 177-182.

(6) Okamoto, Y.; Kubota, T. A model Catalyst Approach to the Effects of the Support on Co-Mo Hydrodesulfurization Catalysts. Catal. Today 2003, 86, 31-43.

(7) Leliveld, R. G.; van Dillen, A. J.; Geus, J. W.; Koningsberger, D. C. Structure and Nature of the Active Sites in CoMo Hydrotreating Catalysts Conversion of Thiophene. J. Catal. 1998, 175, 108-116.

(8) Daage, M.; Chianelli, R. R. Structure-Function Relations in Molybdenum Sulfide Catalysts: The "Rim-Edge" Model. J. Catal. 1994, 149, 414-427.

(9) Surisetty, V. R.; Hu, Y.; Dalai, A. K.; Kozinski, J. Structural Characterization and Catalytic Performance of Alkali (K) and Metal 
(Co and $\mathrm{Rh}$ )-promoted $\mathrm{MoS}_{2}$ Catalysts for Higher Alcohols Synthesis. Appl. Catal., A 2011, 392, 166-172.

(10) Aritani, H.; Fukuda, O.; Miyaji, A.; Hasegawa, S. Structural Change of Molybdenum on Silica-Alumina in Contact with Propene studied by ESR and Mo L $\mathrm{III}_{\mathrm{II}}$-edge XANES. Appl. Surf. Sci. 2001, 180, 261-269.

(11) Yoon, T. H.; Johnson, S. B.; Benzerara, K.; Doyle, C. S.; Tyliszczak, T.; Shuh, D. K.; Brown, G. E., Jr. In Situ Characterization of Aluminum-Containing Nanoparticle-Aqueous Suspensions Using Scanning Transmission X-ray Microscopy. Langmuir 2004, 20, 10361-10366.

(12) Bazin, D.; Kovàcs, I.; Guczi, L.; Parent, P.; Laffon, C.; De Groot, F.; Ducreux, O.; Lynch, J. Genesis of $\mathrm{Co} / \mathrm{SiO}_{2}$ Catalysts: XAS Study at the Cobalt $\mathrm{L}_{\mathrm{III}, \mathrm{II}}$ Absorption Edges. J. Catal. 2000, 189, 450-462.

(13) de Groot, F. M. F.; Kotani, A. Core Level Spectroscopy of Solids; Taylor \& Francis: New York, 2008.

(14) de Groot, F. M. F. Multiplet Effects in X-ray Spectroscopy.

Coord. Chem. Rev. 2005, 249, 31-63.

(15) de Groot, F. M. F.; de Smit, E.; van Schooneveld, M. M.; Aramburo, L. R.; Weckhuysen, B. M. In-situ Scanning Transmission XRay Microscopy of Catalytic Solids and Related Nanomaterials. ChemPhysChem 2010, 11, 951-962.

(16) van der Bij, H. E.; Aramburo, L. R.; Arstad, B.; Dynes, J. J.; Wang, J.; Weckhuysen, B. M. Phosphatation of Zeolite H-ZSM-5: A Combined Microscopy and Spectroscopy Study. ChemPhysChem 2014, 15, 283-292.

(17) Aramburo, L. R.; Ruiz-Martinez, J.; Sommer, L.; Zandbergen, H. W.; Olsbye, U.; de Groot, F. M. F.; Weckhuysen, B. M. X-Ray Imaging of SAPO-34 Molecular Sieves at the Nanoscale: Influence of Steaming on the Methanol-to-Hydrocarbons Reaction. ChemCatChem 2013, 5, 1386-1394.

(18) de Smit, E.; Swart, I.; Creemer, J. F.; Hoveling, G. H.; Gilles, M. K.; Tyliszczak, T.; Kooyman, P. J.; Weckhuysen, B. M.; de Groot, F. M. F. Nanoscale Chemical Imaging of a Working Catalyst by Scanning Transmission X-ray Microscopy. Nature 2008, 456, 222-226.

(19) Vendelbo, S. B.; Kooyman, P. J.; Creemer, J. F.; Morana, B.; Mele, L.; Dona, P.; Nelissen, B. J.; Helveg, S. Method for Local Temperature Measurement in a Nanoreactor for In-Situ HighResolution Electron Microscopy. Ultramicroscopy 2013, 133C, 72-79.

(20) Jacobsen, C.; Wirick, S.; Flynn, G.; Zimba, C. J.; Soft X-ray, J. Spectroscopy from Image Sequences with Sub-100 nm Spatial Resolution. J. Microsc. 2000, 197, 173-184.

(21) de Groot, F. M. F.; Abbate, M.; van Elp, J.; Sawatzky, G. A.; Ma, Y. J.; Chen, C. T.; Sette, F. Oxygen 1s and Cobalt 2p X-ray Absorption of Cobalt Oxides. J. Phys.: Condens. Matter 1993, 5, 2277-2288.

(22) Afanasiev, P.; Matsubayashi, N.; Piccolo, L. S K-Edge EXAFS Study of the Hydrogen Trapping by Amorphous Cobalt Oxosulfide. Photon Factory Activity Report 2006, 24, Part B.

(23) Bare, S. R.; Mitchell, G. E.; Maj, J. J.; Vrieland, G. E.; Gland, J. L. Local Site Symmetry of Dispersed Molybdenum Oxide Catalysts: XANES at the Mo L $\mathrm{L}_{2,3}$-edges. J. Phys. Chem. 1993, 97, 6048-6053.

(24) Bare, S. R. Surface Structure of Highly Dispersed $\mathrm{MoO}_{3}$ on $\mathrm{MgO}$ using In-Situ Mo $\mathrm{L}_{3}$-Edge XANES. Langmuir 1998, 14, 15001504.

(25) Lede, E. J.; Requejo, F. G.; Pawelec, B.; Fierro, J. L. G. XANES Mo L-Edges and XPS Study of Mo Loaded in HY Zeolite. J. Phys. Chem. B 2002, 106, 7824-7831.

(26) Zafeiratos, S.; Dintzer, T.; Teschner, D.; Blume, R.; Hävecker, M.; Knop-Gericke, A.; Schlögl, R. Methanol Oxidation over Model Cobalt Catalysts: Influence of the Cobalt Oxidation State on the Reactivity. J. Catal. 2010, 269, 309-317.

(27) Doyle, C. S.; Traina, S. J.; Ruppert, H.; Kendelewicz, T.; Rehr, J. J.; Brown, G. E., Jr. XANES Studies at the Al K-Edge of AluminiumRich Surface Phases in the Soil Environment. J. Synchrotron Radiat. 1999, 6, 621-623. 